\title{
Mobile Medical Units: An alternate Pathway to address the burden of Non Communicable disease in Urban Slums of India
}

\author{
Ayesha Siddiqua Nawaz ${ }^{1}$, Shailendra Kumar B. Hegde ${ }^{2}$, Vivek Pathania ${ }^{3}$, Hardeep Singh Bambhrah ${ }^{4}$
}

${ }^{1}$ Chief Manager- Clinical Operations, Piramal Swasthya Mangement and Research Institute, Hyderabad; ${ }^{2} \mathrm{Head}$, Public Health Innovations, Piramal Swasthya Mangement and Research Institute, Hyderabad; ${ }^{3}$ Intern, Piramal Swasthya Mangement and Research Institute, Hyderabad; ${ }^{4}$ General Manger Head Assam and North East, Piramal Swasthya Mangement and Research Institute, Hyderabad

\begin{tabular}{|c|c|c|c|c|c|c|c|c|}
\hline Abstract & Introduction & hethodology & Results & Conclusion & References & ion & \multicolumn{2}{|c|}{ Tables / Figures } \\
\hline \multicolumn{9}{|c|}{ ding Autho } \\
\hline \multicolumn{8}{|c|}{$\begin{array}{l}\text { Dr. Ayesha S Nawaz, Chief Manager- Clinical Operations, Clinical Domain, Piramal Swasthya } \\
\text { Mangement and Research Institute, 3rd Floor, No 6-3-1112, Oyster Complex, Somajiguda, } \\
\text { Hyderabad, Telangana } 500016 \\
\text { E Mail ID: Ayesha.siddiqua@ @iramalswasthya.org }\end{array}$} & 口itis \\
\hline
\end{tabular}

\section{Citation}

Nawaz AS, Hegde SKB, Pathania V, Bambhrah HS. Mobile Medical Units: An alternate Pathway to address the burden of Non Communicable disease in Urban Slums of India. Indian J Comm Health. 2021;33(1):217-221. https://doi.org/10.47203/IJCH.2021.v33i01.032

Source of Funding: Nil Conflict of Interest: None declared

\section{Article Cycle}

Received: 07/12/2021; Revision: 15/01/2021; Accepted: 04/03/2021; Published: 31/03/2021

This work is licensed under a Creative Commons Attribution 4.0 International License.

\section{Abstract}

Background: In India despite the increase in health coverage, a small but significant proportion of people in several parts of the country still do not get access to health care services. Mobile Medical Units (MMUs) are a key service strategy to reach such vulnerable population. The present study intends to know the socio-demographic profile of population attending the MMU and the prevalence of Non-Communicable disease (NCD) among them. Materials and Methods: The MMU are located at five different locations in two states. The MMU is equipped to provide primary health care services, essential lab investigations, medications and counselling. The secondary data of beneficiaries attending the MMU during March 2018 to March 2019 was analysed. Results: A total of 84,239 beneficiaries attended the MMU, which comprised of $39 \%$ males and $61 \%$ females. There were 55,934 beneficiaries aged 30 years and above. Out of these majority (62.6\%) were females and $44.4 \%$ beneficiaries were aged between 30 to 45 years. The prevalence of Diabetes and Hypertension among the beneficiaries above 30 years of age was $38.8 \%$ and $46.2 \%$ respectively. Conclusion: MMU can help in delivering quality health services to the vulnerable population and help early diagnosis of NCD.

\section{Keywords}

Non Communicable Diseases; Risk Factors; Screening; Mobile Health Units; Urban Health; Urban Slums

\section{Introduction}

India's health-care system encounters one of the most challenging task of addressing the needs of the most vulnerable population. Amid lack of an adequate health care infrastructure to address the health care needs, it is critical to find alternatives to deliver basic primary care health services to all. Despite improvement in coverage, reaching hard to reach areas remains a challenge. (1) To address this problem, use of Mobile Medical Units (MMU) to deliver primary care in rural and underserved areas appears to be a relevant alternative. (2)

Usually rural population migrate to cities and settle in urban slums. The transition results in lifestyle modifications which are risk factors for various NCD. (3) Piramal Swasthya Management and Research 
Institute, a not for profit organization, through one of its projects provides primary healthcare services to the residents of urban slums where the public health services are either non-existent or weak.

\section{Aims \& Objectives}

1. To know the socio-demographic profile of population attending the MMU.

2. To estimate the prevalence of NonCommunicable disease (NCD) among the residents of Urban Slums.

\section{Material \& Methods}

Study Type: Cross sectional study based on secondary data of the project. The study used deidentified secondary data of the MMU from March 2018 to March 2019.

Study Population: Under this Corporate social responsibility Project in collaboration with Ujjivan Financial Services Limited there were five Mobile Medical Units (MMU) in two states, Karnataka and Maharasthra at five locations in Bangalore (two locations), Mumbai, Pune and Nasik. 22 urban slums at each location which lacked or had limited access to health care facilities were identified and $\mathrm{MMU}$ visited these service points every month. The MMU comprised of a doctor, nurse, pharmacist and a pilot (driver). The MMU provided primary health care services, essential laboratory investigations and medications free of cost to people residing in urban slums.

The patient details were maintained as electronic medical records and patients were informed that the data can be used for secondary research purpose before entering their information in application.

Inclusion Criteria: All registered patients with age equal to or greater than 30 years were considered in the study. Exclusion Criteria: Incomplete entries were excluded.

Ethical Approval: The study was approved by the Institutional Ethical Committee of the Organization.

Data Analysis: For the purpose of analysis, MS excel was used. Chi-Square test was used to determine association between the variables.

Working Definition: Variables which were considered for analysis include, respondent's current age (30-45, 46-60,>= 61 years); sex (male, female); Body Mass Index (Kg/M2)Blood pressure (systolic \& diastolic); random blood sugar; alcohol intake; smoking status.

Based on random blood sugar reading respondents were divided into normal Blood sugar (<=199mg/dl), and Blood sugar in Diabetes range $(>=200 \mathrm{mg} / \mathrm{dl})$. (4) Self-reported cases of diabetes were added to diabetes category. Based on Blood Pressure measurements hypertension was divided into normal (systolic $<120$ \& diastolic <80), prehypertensive (systolic 120-139 or diastolic $80-89$ ) and hypertensive (systolic $>=140$ or diastolic $>=90$ ). (5) Self-reported hypertension was added to hypertensive category.

Based on height and weight measurements BMI was calculated and divided into underweight $(<18.5$ $\mathrm{kg} / \mathrm{m} 2)$, normal $(18.5 \mathrm{~kg} / \mathrm{m} 2-22.9 \mathrm{~kg} / \mathrm{m} 2)$, overweight $(23.0 \mathrm{~kg} / \mathrm{m} 2-24.9 \mathrm{~kg} / \mathrm{m} 2)$ and obese $(>=25 \mathrm{~kg} / \mathrm{m} 2)$ categories. (6)

\section{Results}

During the period of one year, a total of 84,239 beneficiaries were provided services through these five MMUs, out of which 55,934 patients were over the age of 30 years and hence included in the study. Of these, $62.6 \%$ were females and $37.4 \%$ were males. Majority of the beneficiaries $(44.4 \%)$ were in the age group of 30 to 45 years.

The prevalence of hypertension was $46.2 \%$. From (Table 1), it can be seen that hypertension status was significantly associated with factors like gender, agegroup, body mass index, and alcohol and tobacco intake. Hypertension was more prevalent in males $(39.2 \%)$ as compared to females (35.1\%). The prevalence of hypertension was found to increase with increasing age. Also prevalence of hypertension was high among study subjects who were overweight and obese.

A total of 21568 beneficiaries were tested for RBS out of which $38.8 \%$ had Diabetes. From (Table 2), it can be seen that the Diabetes status was found to be significantly associated with $(p<0.05)$ age-group, body mass index, tobacco and alcohol intake. Prevalence of having diabetes was more (48.1\%) among the beneficiaries aged 46 to 60 years when compared to other age groups. Majority of the study subjects who were using tobacco in any form had diabetes (62.8\%) when compared to non-tobacco users (37.7\%). Similarly, majority of individuals with alcohol consumption had diabetes (47.1\%).

\section{Discussion}

The quality of life in urban slums is quite challenging; as the standard of hygiene and living conditions are often compromised due to poverty and illiteracy. In addition to communicable diseases it has been seen that NCDs like diabetes and hypertension are on the 
rise in slum areas due to lifestyle changes.(7) The diabetes prevalence in our study is high as compared to various studies from urban slums. $(8,9)$ It may be due to the age group taken which is above 30 years; as with increasing age there are higher chances of having diabetes. The study shows that individuals who were underweight were equally prone to diabetes as obese Higher prevalence of hypertension in slums is also being seen.(10) In our study, the prevalence of hypertension was high among obese individuals. Observations from our study highlight that urban slums have high prevalence of NCD and their risk factors and there is a strong need for proper healthcare system to identify NCD at the earliest as these areas are more likely to be neglected.

It can be seen from our study that people from urban slums are having high prevalence of both diabetes and hypertension and providing primary health care services through MMUs can be an alternative for achieving universal health care in these areas. Keeping in mind the epidemiological transition and high likelihood of these areas to be burdened by NCDs, MMUs can provide health services to the vulnerable population residing in the urban slums close to their door steps. Literature provides evidence that MMUs are of great importance in providing free medical services with laboratory diagnostic facilities.(2) Our study reinforces the importance of MMUs in achieving universal coverage by enabling health care delivery to the neglected population of urban slums. They also help in early diagnosis of NCDs, thereby preventing complications.

\section{Conclusion}

Out of 55,934 patients aged 30 years and above, $62.6 \%$ were females and $37.4 \%$ were males. Majority of the beneficiaries (44.4\%) were in the age group of 30 to 45 years. The prevalence of Hypertension and Diabetes was $46.2 \%$ and $38.8 \%$ respectively. The NCD status was significantly associated with factors like age-group, body mass index, and alcohol and tobacco intake.

\section{Recommendation}

Mobile Medical Units support in addressing the inequity and achieving universal health coverage in areas like urban slums where basic health facilities are not available. MMUs could be the potential alternative in delivering quality health services to the vulnerable population and helping with early diagnosis of Non-communicable diseases.

\section{Relevance of the study}

The study provides information on the emerging epidemic of NCDs in urban slums, the prevailing risk factors and burden of NCD regarding which there is limited literature available. Our study shows a high prevalence of NCD by screening of individuals aged 30 years and above which otherwise would have gone undetected and reinforces the need for alternatives like MMU to reach the unreached and support early diagnosis.

\section{Authors Contribution}

All the authors have contributed significantly to the study.

\section{Acknowledgement}

The authors acknowledge the medical and paramedical staff of Ujjivan project, Operations team members of Ujjivan project and the CSR team of Ujjivan Financial Services Limited for their support and also all the beneficiaries attending the MMU at these locations.

\section{References}

1. Operational Guidelines for Mobile Medical Units. Ministry of Health and Family Welfare Government of India, Available from: https://nhm.gov.in/New Updates 2018/NHM Componen ts/Health System Stregthening/MMU/Mobile Medical U nits.pdf [Accessed on 02 Feb 2021]

2. Kumar M, Kiran A, Kujur M. Assessment of mobile medical units functioning in Jharkhand, India. Int J Community Med Public Health 2016;3:878-80.

3. Parmar VB, Rupani MP, Trivedi AV. Social Determinants of Diabetes and Hypertension in an Urban Slum of Gujarat, Western India: A Cross-Sectional Study. Online J Health Allied Scs. 2019;18(1):1. Available at URL: https://www.ojhas.org/issue69/2019-1-1.html .

4. American Diabetes Association. 2. Classification and Diagnosis of Diabetes: <i>Standards of Medical Care in Diabetes-2020</i>. Diabetes Care. 2020;43(Suppl 1):S14S31. doi: 10.2337/dc20-S002. PMID: 31862745.[PubMed]

5. Chobanian AV, Bakris GL, Black HR, Cushman WC, Green LA, Izzo JL Jr, Jones DW, Materson BJ, Oparil S, Wright JT Jr, Roccella EJ; National Heart, Lung, and Blood Institute Joint National Committee on Prevention, Detection, Evaluation, and Treatment of High Blood Pressure; National High Blood Pressure Education Program Coordinating Committee. The Seventh Report of the Joint National Committee on Prevention, Detection, Evaluation, and Treatment of High Blood Pressure: the JNC 7 report. JAMA. 2003;289(19):2560-72. doi: 10.1001/jama.289.19.2560. Epub 2003 May 14. Erratum in: JAMA. 2003 Jul 9;290(2):197. PMID: 12748199.[PubMed].

6. Pan WH, Yeh WT. How to define obesity? Evidence-based multiple action points for public awareness, screening, and 
treatment: an extension of Asian-Pacific recommendations.

Asia Pac J Clin Nutr. 2008;17(3):370-4. PMID: 18818155.[PubMed].

7. Abdi S, Wadugodapitiya A, Bedaf S, George CE, Norman G, Hawley $M$, de Witte L. Identification of priority health conditions for field-based screening in urban slums in Bangalore, India. BMC Public Health. 2018;18(1):309. doi: 10.1186/s12889-018-5194-2. PMID: 29499698; PMCID: PMC5833095.[PubMed]

8. Misra A, Pandey RM, Devi JR, Sharma R, Vikram NK, Khanna $N$. High prevalence of diabetes, obesity and dyslipidaemia in urban slum population in northern India. Int J Obes Relat Metab Disord. 2001;25(11):1722-9. doi:
[Mobile Medical Units...] | Nawax AS et al 10.1038/sj.ijo.0801748. Erratum in: Int J Obes Relat Metab Disord. 2002 Sep;26(9):1281. PMID: 11753596.[PubMed]

9. Patil RS, Gothankar JS. Assessment of risk of type 2 diabetes using the Indian Diabetes Risk Score in an urban slum of Pune, Maharashtra, India: a cross-sectional study. WHO South East Asia J Public Health. 2016;5(1):53-61. doi: 10.4103/2224-3151.206555. PMID: 28604399.[PubMed].

10. Rathod ND, Lilare RR. Study of prevalence of hypertension in an adult population of age group 40 to 60 years in an urban slum of Mumbai, Maharashtra, India. Int J Community Med Public Health. 2018;5(5) DO 10182032394-6040ijcmph20181711

\section{Tables}

\section{TABLE 1 ASSOCIATION OF HYPERTENSION STATUS WITH SOCIO-DEMOGRAPHIC AND} ANTHROPOMETRIC MEASURES.

\begin{tabular}{|c|c|c|c|c|c|}
\hline \multirow[t]{2}{*}{ Variables } & \multicolumn{5}{|c|}{ Hypertension status N (\%) } \\
\hline & Normal & Pre-Hypertensive & Hypertensive & $x^{2}$ & $p$-value \\
\hline \multicolumn{6}{|l|}{ Gender } \\
\hline Female & $4810(21.4)$ & 7883 (35.1) & 9797 (43.5) & \multirow[t]{4}{*}{410.72} & \multirow[t]{4}{*}{$<0.001$} \\
\hline Male & 1484 (10.4) & 5581 (39.2) & 7181 (50.4) & & \\
\hline Transgender & $3(0.0)$ & $0(0.0)$ & $4(0.0)$ & & \\
\hline Total & 6295 (17.1) & $13466(36.7)$ & $16982(46.2)$ & & \\
\hline \multicolumn{6}{|l|}{ Age-Groups } \\
\hline $30-45$ & $3626(23.7)$ & $6462(42.3)$ & $5186(34.0)$ & \multirow[t]{4}{*}{1800} & \multirow[t]{4}{*}{$<0.001$} \\
\hline $46-60$ & $1944(14.0)$ & $4598(33.2)$ & 7327 (52.8) & & \\
\hline$>=61$ & 725 (9.5) & 2406 (31.6) & 4469 (58.9) & & \\
\hline Total & 6295 (17.1) & 13466 (36.7) & $16982(46.2)$ & & \\
\hline \multicolumn{6}{|l|}{ BMI } \\
\hline Underweight & 553 (16.1) & 1817 (52.9) & 1065 (31.0) & \multirow[t]{5}{*}{2000} & \multirow[t]{5}{*}{$<0.001$} \\
\hline Normal & $2604(23.2)$ & $4336(38.6)$ & $4302(32.2)$ & & \\
\hline Overweight & $664(11.8)$ & $2042(36.3)$ & 2923 (51.9) & & \\
\hline Obese & $2423(15.2)$ & 4965 (31.2) & 8546 (55.6) & & \\
\hline Total & $6244(17.2)$ & $13160(36.3)$ & $16836(46.5)$ & & \\
\hline \multicolumn{6}{|l|}{ Tobacco intake status } \\
\hline Tobacco usage in any form & $303(23.9)$ & $485(38.5)$ & 477 (37.7) & \multirow[t]{3}{*}{38.64} & \multirow[t]{3}{*}{$<0.001$} \\
\hline Not taking tobacco & $5990(16.9)$ & $12976(36.6)$ & $16503(46.5)$ & & \\
\hline Total & 6293 (17.1) & $13461(36.6)$ & $16980(46.2)$ & & \\
\hline \multicolumn{6}{|l|}{ Alcohol status } \\
\hline Alcohol intake & $84(12.0)$ & $296(42.3)$ & $320(45.7)$ & \multirow[t]{3}{*}{13.82} & \multirow[t]{3}{*}{$<0.001$} \\
\hline Not taking alcohol & $6202(17.3)$ & $13099(36.5)$ & $16587(46.2)$ & & \\
\hline Total & $6286(17.2)$ & $13395(36.6)$ & $16907(46.2)$ & & \\
\hline
\end{tabular}

TABLE 2 ASSOCIATION OF DIABETES STATUS WITH SOCIO-DEMOGRAPHIC AND ANTHROPOMETRIC MEASURES.

\begin{tabular}{|c|c|c|c|c|}
\hline Variable & Normal & Diabetes & $x^{2}$ & $P$ value \\
\hline \multicolumn{5}{|l|}{ Gender } \\
\hline Female & 7735 (61.6) & 4819 (38.4) & \multirow[t]{4}{*}{3.55} & \multirow[t]{4}{*}{0.169} \\
\hline Male & $5458(60.6)$ & 3550 (39.4) & & \\
\hline Transgender & $5(83.3)$ & 1 (16.7) & & \\
\hline Total & $13,198(61.2)$ & $8370(38.8)$ & & \\
\hline \multicolumn{5}{|l|}{ Age-Groups } \\
\hline $30-45$ & $5461(75.9)$ & $1730(24.1)$ & \multirow[t]{2}{*}{1000} & \multirow[t]{2}{*}{$<0.001$} \\
\hline $46-60$ & 4940 (51.9) & $4573(48.1)$ & & \\
\hline
\end{tabular}


INDIAN JOURNAL OF COMMUNITY HEALTH / VOL 33 / ISSUE NO 01 / JAN- MAR 2021

\begin{tabular}{|l|l|}
\hline$>=61$ \\
\hline Total \\
BMI
\end{tabular}

Underweight

Overweig

Obese

Total

Tobacco intake status

Tobacco usage in any form

Not taking tobacco

Total

Alcohol status

Alcohol intake

Not taking alcohol

Total
2797 (57.5)

13,198 (61.2)

1023 (57.9)

3858 (59.9)

2101 (69.1)

6051 (59.9)

13033 (61.0)

351 (37.2)

12847 (62.3)

13198 (61.2)

238 (52.9)

12900 (61.3)

13138 (61.2)
[Mobile Medical Units...] | Nawax AS et al 2067 (42.5) 8370 (38.8)

743 (42.1)

2585 (40.1)

939 (30.9)

4048 (40.1)

8315 (39.0)

592 (62.8)

7778 (37.7)

8370 (38.8)

212 (47.1)

8139 (38.7)

8351 (38.9)

\begin{tabular}{|c|c|c|}
\hline 99.5 & $<0.001$ \\
\hline 239.8 & $<0.001$ \\
\hline 20.44 & $<0.001$ \\
\hline & \\
\hline
\end{tabular}

